\title{
The Effect of Dexamethasone on Chronic Pulmonary Oxygen Toxicity in Infant Mice
}

\author{
N. OHTSU, R. L. ARIAGNO, T. E. SWEENEY, L. DAVIS, L. MOSES, R. PETRICEKS, I. DAEHNE, \\ K. BENSCH, AND W. H. NORTHWAY, JR. \\ Departments of Radiology, Pathology, Pediatrics, Stanford University Medical Center, Stanford, California 94305
}

\begin{abstract}
The effect of dexamethasone $(0.1,1$, and 5 $\mathrm{mg} / \mathrm{kg} / \mathrm{d}$ given subcutaneously from d 14-18) was tested in infant mice continuously exposed from birth to either humidified air or $80 \%$ oxygen. Dexamethasone significantly decreased lung wet wt $(p<0.01)$, lung water $(p<0.021)$, lung dry wt, protein, and DNA $(p<0.001)$ in both airand oxygen-exposed animals. Dexamethasone, however, had no effect on lung compliance measured after animals were killed on d 18. It also had no effect on the increase in the blood-air barrier thickness or decrease in the blood-air exchange surface area seen in the $80 \%$ oxygen-exposed mice. Dexamethasone decreased thymus gland wt $(p<$ $0.001)$, body wt gain $(p<0.001)$, brain wt $(p<0.001)$ and lung lymphocytes $(p<0.05)$ in both air- and oxygenexposed animals. The effect of $1 \mathrm{mg} / \mathrm{kg}$ and $5 \mathrm{mg} / \mathrm{kg}$ of the drug could not be differentiated. During the $4 \mathrm{~d}$ of drug administration, one air- and one oxygen-exposed animal died; both received $5 \mathrm{mg} / \mathrm{kg} / \mathrm{d}$ of dexamethasone; microscopic and culture evidence of infection was not found. If dexamethasone causes similar effects in human infants with bronchopulmonary dysplasia, it should be used with great caution even for short-term clinical management. (Pediatr Res 25:353-359, 1989)
\end{abstract}

\section{Abbreviations}

BPD, bronchopulmonary dysplasia $\mathrm{PV}$, pressure volume

The experience of Mammel et al. $(1,2)$ and Avery et al. (3) suggest that short term utilization of dexamethasone at 2 to 6 wk of age in patients with BPD can improve lung function and hasten weaning from mechanical ventilation. Complications have, however, been associated with this treatment, including pneumothorax, sepsis, necrotizing enterocolitis, hyperglycemia, and hypertension $(2,4-7)$. The overall beneficial effect of corticosteroid therapy in this setting is not clear.

The newborn mouse chronically exposed to 80 to $100 \%$ oxygen develops a pulmonary disease morphologically similar to BPD $(8,9)$. Hypothesizing that dexamethasone could be of use to treat BPD, we have examined the acute effects of dexamethasone on physical, biochemical, and morphometric parameters of chronic pulmonary oxygen toxicity induced in newborn mice by continuous exposure to $80 \%$ oxygen for $18 \mathrm{~d}$. Insofar as possible, the duration of development of the chronic lung disease (18 d), the dose of dexamethasone $(0.1,1.0$, and $5 \mathrm{mg} / \mathrm{kg})$, and duration of usage $(4 \mathrm{~d})$ were chosen to approximate those parameters re-

Received June 18, 1987; accepted November 16, 1988.

Correspondence and reprints to Dr. William H. Northway, Department of Radiology, Stanford University Medical Center, Stanford, CA 94305.

Supported by NIH Grant HL 30394. ported in the clinical studies of Mammel et al. $(1,2)$ and Avery et al. (3).

\section{METHODS}

Animal selection, environment, and drug administration. In each experiment, two litters of naturally born C57BL mice were weighed and sex identified within $24 \mathrm{~h}$ of birth. Natural litter size was reduced to five by selecting the five animals with the highest birth wt. Each of the five newborn mice was marked and assigned a serial number which determined the treatment assignment at $14 \mathrm{~d}$. Each litter with the mother was placed in a plastic mouse cage in a controlled environment chamber within $24 \mathrm{~h}$ of birth. The chamber ( 198 liter capacity) received either a constant humidified supplemental oxygen concentration of $80 \%$ at normal atmospheric pressure or humidified air at a flow rate of 7 10 liter/min. Nursing mothers were exchanged between the control and experimental environment every $24 \mathrm{~h}$ to reduce possible differences in nursing ability, as well as to avoid oxygen intoxication of the mothers. The controlled environment chambers incorporate lock and glove ports enabling exchange of the mothers and manipulation of the newborn animals within the chambers without altering the environment. The standard conditions of the animals, controlled environment chambers, and the monitoring of the environmental and control atmospheres have been previously described in detail (8-9).

The control newborn litter was exposed to humidified air for $14 \mathrm{~d}$ without drug administration. The experimental litter was exposed to humidified $80 \%$ oxygen at normal atmospheric pressure for $14 \mathrm{~d}$ without drug administration to allow lung injury to develop (10). During the following 4-d exposure period, two animals in each environment served as controls and received subcutaneous injections of either saline or carrier daily. Three in each environment received dexamethasone sodium phosphate in a single subcutaneous injection daily for $4 \mathrm{~d}$. One animal in each environment received the drug at a low dose $(0.1 \mathrm{mg} / \mathrm{kg})$, one at an intermediate dose $(1 \mathrm{mg} / \mathrm{kg})$, and one at a high dose $(5 \mathrm{mg} /$ $\mathrm{kg}$ ). Initially, $10 \mathrm{mg} / \mathrm{kg}$ was tried as the high dose, but it caused significant mortality in the animals. At $24 \mathrm{~h}$ after the fourth administration of the drug, the surviving animals were killed by sodium pentobarbital injection.

Body wt gain, mortality, and morbidity. All animals were weighed at the end of the 14-d exposure period, each day during the 4-d injection period, and when they were killed. Death and morbidity were recorded.

Lung lobe wet and dry wt, total lung lobe collagen, protein, and DNA. When the animal was killed, the trachea was exposed and cannulated with a blunt needle. The thoracic cage was carefully opened, and the hilum of the left upper lobe was ligated and severed. The left upper lobe was weighed and stored at $-20^{\circ} \mathrm{C}$ for subsequent lyophilization and chemical analysis.

After lyophilization for lung dry wt measurement, the left upper lobe was analyzed for total lung hydroxyproline, protein, 
and DNA. Total lung hydroxyproline was measured by modification of the method of Huszar et al. (11). Total protein was determined by the Lowry method (12). DNA separation was by a modified Kennel procedure (13), and DNA measurement was by Burton's modification of the diphenylamine reaction (14).

Thymus and brain. When the animal was killed, the thymus gland was removed, blotted, and weighed. As dexamethasone produces thymic atrophy, its wt compared to thymus glands in control animals was a measure of drug effect. The brain was removed and weighed when the animal was killed. One hemisphere was preserved in 10\% buffered formalin and examined for intraventricular hemorrhage. The DNA of the other hemisphere of the brain was measured to evaluate brain growth (15).

Infection. The presence of infection was screened for by histologic examination. Blood was obtained from direct heart puncture for bacterial culture when an animal died during the 4-d period of drug treatment if the remains were intact for examination.

Tissue preparation. The right lung and left lower lobe were inflated at a pressure of $20 \mathrm{~cm} \mathrm{H}_{2} \mathrm{O}$ with buffered $3 \%$ glutaraldehyde with the lung in the thoracic cavity. The trachea was then ligated, and lungs and heart were removed en bloc. The lung vol was measured by fluid displacement (16). After fixation in the inflated state, the four lobes were separated. One-third of each of these lobes was minced into 2 - to $3-\mathrm{mm}^{3}$ pieces, and fixation in glutaraldehyde was continued for several d, after which the tissue was rinsed in buffered wash solution and postfixed in $1 \%$ osmium tetroxide. Five random tissue pieces from each lobe were dehydrated in ethanol and embedded in Maraglas (Marblette Co., Long Island City, NY). Sections $1 \mu \mathrm{m}$ thick of three randomly selected blocks from each lobe were prepared for light microscopic examination, and several ultrathin sections from each lobe were mounted on copper grids stained with uranyl acetate and lead citrate for study in a Siemens Elmiskop 101 (Siemens America Inc., Cherry Hill, NJ).

Morphometry. Several methods for data gathering and analysis were used in this study. For the determination of the areas occupied by the alveolar wall and the blood vessels and for the measurement of the lengths of the blood-air barrier, a Hipad Digitizer Interface Board (Houston Instrument, Austin, TX) was used in conjunction with an IBM PC, programmed to provide the area measurements in $\mu \mathrm{m}^{2}$ and the lengths in micrometers (South MicroInstruments, Atlanta, Ga). To facilitate the analyses of the numerous, often complex electron micrographs, three colored lines were drawn over the basal laminae of the alveolar epithelium and vascular endothelium: a blue line followed the basal lamina of the epithelium, a red line followed the basal lamina of the endothelium, and a yellow line marked the length of apposition of the basal lamina of the endothelium with that of the abutting epithelium (i.e. the blood-air exchange surface). Thus, the sum of the length of the blue and yellow lines represented the area covered by epithelial tissue, with the yellow line being the morphometric analogue of the area occupied by the blood-air barrier. The gas diffusion is believed to take place most efficiently across the yellow line. The area surrounded by both red and yellow lines or circled by a red line represented the space occupied by blood vessels. The areas between the red and blue lines were those filled with interstitial tissue. These determinations were made on 28 to 32 electron micrographs of fields that had been randomly photographed as described by Weibel (17, 18). Seven or eight photographs from each lobe were made at a magnification of $2200 \times$, and the prints were enlarged to a final magnification of $8000 \times$. Furthermore, these micrographs were also used to determine the vol density of the cellular elements of the alveolar wall and its interstitial tissue. This was done with a transparent 320-point grid, which, at the magnification of the micrographs, encompassed $2610 \mu \mathrm{m}^{2}$.

For the determination of the numerical incidence of cell types, all of the electron micrographs (1408) were used. In this manner, all of the cells present on a micrograph were identified, including the inflammatory cells.
The proportion of the total lung vol defined as parenchyma was also determined on 16 light microscopic photographs of the lung tissue of the control and experimental animals. For this purpose, photographic fields were randomly selected as described by Weibel, and four photographs from each lobe were made at a magnification of $40 \times$. The prints were enlarged to match a translucent plastic test pattern with 320 points. The final magnification was $715 \times$. Furthermore, the average alveolar size was determined by measuring the least and greatest diameter of the alveolar spaces on $1 \mu \mathrm{m}$ thick sections of the lung from two of the original 10 experiments. A total of 1702 alveolar spaces were measured. The common logarithm of the product of the diameters was computed and averaged for each of the 15 fields evaluated.

In summary, the parameters measured on electron micrographs in this study included the determination of 1 ) the vol density of the total alveolar tissue and capillaries; 2) the area of the blood-air exchange surface; 3 ) the thickness of the blood-air barrier, including the thickness of the endothelial cell, overlying epithelial cell and intervening extracellular space consisting of the basal lamina of the endothelial cell and that of the epithelial cell; and 4) the vol density of inflammatory cells such as polymorphonuclear leukocytes, lymphocytes, and intraalveolar macrophages, platelets, and epithelial cells; the latter cell type was subdivided into type I, type II, and type III pneumocyte with the last mentioned being an intermediate cell between type II and I.

$P V$ studies of the lungs. Seven separate experiments with the same air and $80 \%$ oxygen exposure and treatment regimen of dexamethasone were done to study the PV relationships in the lungs of the experimental and control mice. At the end of the 18-d exposure period, including $4 \mathrm{~d}$ of drug treatment, the animals were anesthesized with $2.5 \mathrm{mg}$ of intraperitoneal pentobarbital, weighed, and attached supine to a small animal board. The trachea was exposed, and a 23-gauge Intramedic luer stub adapter (Becton Dickinson, Rutherford, NJ) was inserted into the trachea through a small incision. The adapter was ligated tightly in place with 3-0 silk suture to provide a tight seal. The Luer Stub Adapter was attached to a 3-way stopcock, which was held in place by a clamp and attached to a second stopcock and Validyne pressure transducer model MP45 (Validyne Engineering Corp., Northridge, CA) and its carrier demodulator, model CD15, which were used for the pressure measurements. A $1-\mathrm{ml}$ Hamilton microliter syringe model 750-LT (Hamilton Co., Reno, NV) was used to deliver incremental vol. The pressure transducer system was calibrated with a $U$-tube water manometer to $5 \mathrm{~V} / 20 \mathrm{~cm}$ of water. The system compliance was measured and was $2.5 \mu \mathrm{L} / \mathrm{cm} \pm 0.09$ SEM throughout the experiments. The vol of the measurement system was $1 \mathrm{~mL}$ from the tip of the tracheal catheter to the pressure transducer (including the stopcocks and connecting tubing).

Pressure measurements before and after removal of the ventral thorax showed no change in pressure. The lungs were kept moist with normal saline placed on the surface of the lungs. The lungs were inflated with $25 \mu \mathrm{L}$ vol increments to approximately 200 $\mu \mathrm{L}$ maximum. After each vol was delivered, a 30-s interval was allowed for pressure stabilization. The maximum pressure used was arbitrarily $20 \mathrm{~cm}$ of water as air leaks had been noted above this pressure in pilot preparations. Air leaks when present were detected by failure of the pressure to stabilize. The vol was then decreased at $25 \mu \mathrm{L}$ increments (with 30-s stabilization intervals), until 0.0 pressure was obtained. The vol was then increased to $25 \mu \mathrm{L}$ and three "simulated tidal vol" cycles were performed. In each cycle, $25-\mu \mathrm{L}$ vol were delivered and then removed. Stabilization intervals of $30 \mathrm{~s}$ were allowed.

After the PV measurements were finished, the lungs were removed from the thorax and inflated with buffered $3 \%$ glutaraldehyde at a pressure of $20 \mathrm{~cm} \mathrm{H}_{2} 0$. The lung vol was measured by fluid displacement (16). The compliance was calculated from the "simulated tidal vol" maneuver (slope at tidal vol between 50 and $25 \mu \mathrm{L}$ above 0 pressure) and from the "full range" of the deflatation curve (vol final-vol initial/pressure final-pressure 
initial). The compliance values were calculated per g body wt and per $\mathrm{mL}$ lung vol.

\section{RESULTS}

The physical, biochemical, and morphometric data can be regarded as coming from eight replications of the same 10-animal experiment. Each complete replicate had two five-animal litters, one exposed to air, the other to $80 \%$ oxygen. A pair of litters began exposure concurrently, were nursed (in 24-h alternation) by the same two mothers, and were killed concurrently. The newborn animals in each litter were assigned serial numbers at birth, and treatment assignment at $14 \mathrm{~d}$ was determined by that number. Thus, if no animals died during exposure or injection in either litter, one experiment gave 10 observations. In the analyses of the biochemical and physical data that follow, the data from the $0.1 \mathrm{mg} / \mathrm{kg}$ dexamethasone dose are not used as they did not differ significantly from control values except in the parameter of thymus wt. Of the 64 remaining observations, five were missing. Three animals died during $80 \%$ oxygen exposure before drug injection, and two died during drug injection. Both of the latter animals received $5 \mathrm{mg} / \mathrm{kg}$ dexamethasone-one in air and one in $80 \%$ oxygen. The other three animals had been assigned to receive $1 \mathrm{mg} / \mathrm{kg}$ dexamethasone. No consistent differences in any variable were seen between animals receiving 1 and $5 \mathrm{mg} / \mathrm{kg}$ of dexamethasone, and these five missing entries were therefore "filled" with the value of the litter mate who received the other dose of dexamethasone.

The 64-observation data set has a very symmetric structure, known in the experimental design literature as a $2 \times 4$ factorial experiment in eight replications. One of the factors, oxygen versus air, is applied to whole litters at a time; the other factor, four kinds of injections, appears at all levels within each litter. This distinction makes the experiment a split-plot factorial design (19). Using the appropriate SE, we found: 1) No statistically significant difference between animals receiving 1 and $5 \mathrm{mg} / \mathrm{kg}$ of dexamethasone. 2) No statistically significant differences between animals receiving saline or carrier. These two results allowed us to treat every animal either as having received dexamethasone or as a control. 3) We also found no significant ( $p$ $=0.05$ ) interaction between atmosphere and drug (i.e. dexamethasone or control). Thus, it is not necessary to discuss separately the effects of dexamethasone on newborn mice raised in the two different atmospheres.

These three findings, true for every variable reported in Tables 1 and 2, permit simple and straightforward analysis of the results. The structure of the data can now be regarded as a $2 \times 2$ factorial experiment (drug condition $\times$ atmosphere condition) with no interaction between the factors. Both Tables 1 and 2 are, therefore, reports of a factorial analysis where the two factors (atmosphere and drug) do not show interactions (20). The means and SE relating to the effects of dexamethasone appear in Table 1.

The drug reduced-in each case by about $10 \%$-lung water, lung wet wt and dry wt, total lung lobe protein, and DNA. All these reductions attained statistical significance. Lung lobe collagen was also reduced, but not significantly. In addition, body wt change during the 4-d injection period was positive in the controls and negative in the dexamethasone-treated animals, the difference being significant.

The drug, at dose $1 \mathrm{mg} / \mathrm{kg}$ and $5 \mathrm{mg} / \mathrm{kg}$, also reduced thymus wt dramatically; the average wt for controls was $41 \mathrm{mg}$, and for dexamethasone-treated animals was $6 \mathrm{mg}$. The smallest dose of dexamethasone, $0.1 \mathrm{mg} / \mathrm{kg}$, was sufficient to reduce thymus wt clearly. In all eight experiments in both atmospheres, animals treated with $0.1 \mathrm{mg} / \mathrm{kg}$ dexamethasone had a smaller thymus than either of the control animals in its litter. The reduction in brain wt-about 5\% - was clearly significant, but brain DNA was not appreciably-nor significantly-affected.

Lung lobe collagen was sharply increased in the oxygen atmosphere, and lung lobe DNA was even more sharply reduced (see Table 2). Finally, brain wt was smaller in the $80 \%$ oxygenexposed animals by nearly $5 \%$, and the difference was significant.

Morphometric variables. Four experiments were selected for complete morphometric study from the same eight experiments that furnished the physical and biochemical data. One animal had suboptimally inflated and preserved lung tissue and was not studied, and three animal deaths reduced the morphometric data available in these four experiments (see Table 3). Due to the incidence of missing data, straightforward ANOVA approaches were unworkable. Therefore, likelihood ratio techniques (of which conventional ANOVA is a special case) were applied. The results appear in Table 3. Data at the lowest dose of dexamethasone have been dropped. The data offer these conclusions: $I$ ) $\mathrm{O}_{2}$ increases the thickness of the blood-air barrier and of the individual layers that make it up (with less certainty attaching to the endothelium) and 2) $\mathrm{O}_{2}$ increases the vol density of the alveolar wall and decreases the blood-air exchange surface. Less significant effects of oxygen on numbers of epithelial cells of type II and type III occurred, with the former decreasing and the latter increasing. None of these oxygen-affected variables showed dexamethasone effects. Dexamethasone did produce a significant decrease in lymphocytes in the lung.

The average alveolar size, measured in two experiments, was greater in oxygen by 0.26 to $0.56 \mu \mathrm{m}^{2}(p<0.01)$ but was not affected by dexamethasone. Microscopic evidence of infection was not seen in any animal. Intraventricular hemorrhage was not seen.

Table 1. Effects of dexamethasone on newborn mice*

\begin{tabular}{|c|c|c|c|c|c|}
\hline \multirow[b]{2}{*}{ Parameter } & \multirow{2}{*}{$\begin{array}{l}\text { Mean value } \\
\text { (all animals) } \\
\quad(n=59)\end{array}$} & \multirow{2}{*}{$\begin{array}{l}\text { Dexamethasone - control } \uparrow \text { : } \\
\text { difference of means }\end{array}$} & \multirow[b]{2}{*}{ SE } & \multicolumn{2}{|c|}{ Significance } \\
\hline & & & & $t$ & $p$ \\
\hline Lung lobe water & $23.3 \mathrm{mg}$ & -2.17 & 0.80 & 2.71 & 0.021 \\
\hline Lung lobe wet wt & $28.9 \mathrm{mg}$ & -2.9 & 0.91 & 3.19 & 0.01 \\
\hline Lung lobe dry wt & $5.67 \mathrm{mg}$ & -0.6 & 0.13 & 4.61 & 0.001 \\
\hline Lung lobe protein & $35.5 \mathrm{mg} /$ lobe & -4.75 & 1.11 & 4.28 & 0.001 \\
\hline Lung lobe DNA & $244 \mu \mathrm{g} /$ lobe & -32.0 & 7.9 & 4.05 & 0.001 \\
\hline Lung lobe collagen & $131 \mu \mathrm{g} /$ lobe & -10.4 & 7.6 & 1.36 & NS \\
\hline Body wt change (\%) during injection period & $+1.8 \%$ & $-12 \%$ & $1.1 \%$ & 10.91 & 0.001 \\
\hline Thymus wt & $23.8 \mathrm{mg}$ & -35 & 1.45 & 24.1 & 0.001 \\
\hline Brain hemisphere DNA & $542 \mu \mathrm{g}$ & -5.5 & 17.0 & 0.32 & NS \\
\hline Brain wt & $342 \mathrm{mg}$ & -15.0 & 3.2 & 4.68 & 0.001 \\
\hline
\end{tabular}

* The absence of significant drug-atmosphere interaction allows using all animals to assess the drug effect: one group as dexamethasone treated and the other as controls. A standard $2 \times 2$ factorial analysis is used $(20)$.

+ Average value of animals recciving 1 or $5 \mathrm{mg} / \mathrm{kg}$ dexamethasone minus average value of animals receiving saline or carrier control, averaged across both $80 \% \mathrm{O}_{2}$ and air. 
Table 2. Effects of $80 \%$ oxygen on newborn mice*

\begin{tabular}{|c|c|c|c|c|c|}
\hline \multirow[b]{2}{*}{ Parameter } & \multirow{2}{*}{$\begin{array}{c}\text { Mean value } \\
\text { (all animals) } \\
\quad(n=59)\end{array}$} & \multirow{2}{*}{$\begin{array}{c}\mathrm{O}_{2} \text {-airt: } \\
\text { difference of means }\end{array}$} & \multirow[b]{2}{*}{ SE } & \multicolumn{2}{|c|}{ Significance } \\
\hline & & & & $t$ & $p$ \\
\hline Lung lobe water & $23.3 \mathrm{mg}$ & +1.35 & 0.80 & 1.68 & NS \\
\hline Lung lobe wet wt & $28.9 \mathrm{mg}$ & +1.40 & 0.88 & 1.59 & NS \\
\hline Lung lobe dry wt & $5.67 \mathrm{mg}$ & +.05 & 0.12 & 0.42 & NS \\
\hline Lung lobe protein & $35.5 \mathrm{mg}$ & -1.66 & 1.58 & 1.05 & NS \\
\hline Lung lobe DNA & $244 \mu \mathrm{g}$ & -77.8 & 9.64 & 8.07 & $<.001$ \\
\hline Lung lobe collagen & $131 \mu \mathrm{g}$ & +24.5 & 4.97 & 4.92 & $<.001$ \\
\hline Body wt change $(\%)$ during injection period & $+1.8 \%$ & $-2.13 \%$ & $1.34 \%$ & 1.59 & NS \\
\hline Thymus wt & $23.8 \mathrm{mg}$ & +3.5 & 1.9 & 1.84 & NS \\
\hline Brain hemisphere DNA & $542 \mu \mathrm{g}$ & -27.0 & 16.0 & 1.69 & NS \\
\hline Brain wt & $342 \mathrm{mg}$ & -16.0 & 3.4 & 4.71 & $<.01$ \\
\hline
\end{tabular}

* The absence of significant drug-atmosphere interactions allows using all animals to assess the $\mathrm{O}_{2}$ effect: one group breathing $80 \% \mathrm{O}_{2}$ and one group breathing room air. A standard $2 \times 2$ factorial analysis is used $(20)$.

$\dagger$ Average value of $80 \%$ oxygen-exposed animals minus average value of air-exposed animals, averaged across injection categories.

$P V$ variables. "Simulated tidal vol" compliance, divided by body wt, is the subject of Figure 1, which shows box plots of the data. A box plot is an abbreviated representation of the distribution of sample values. The horizontal line in the interior of the box denotes the median of the observations. The lower edge of the box denotes the lower quartile, and upper edge the upper quartile. The additional marks give some information about the distribution above and below the two quartiles. Figure 1 shows that the simulated tidal vol compliance is greater in those lungs exposed to $80 \%$ oxygen than in those exposed to air $(p<0.02)$, and the presence (or dose) of dexamethasone exerts no visible effect on this compliance.

Figure 2 displays the corresponding information for full-range compliance. Again, values are elevated in the lungs exposed to $80 \%$ oxygen $(p<0.02)$, and no effects of the drug are visible. Comparison of the figures indicates that the oxygen effect is larger for simulated tidal vol than for full-range compliance as the vertical displacement of the gray (from the white) box plots is greater for the former (in Fig. 1) than for the latter (in Fig. 2).

\section{DISCUSSION}

In this study, the newborn mice exposed to $80 \%$ oxygen developed changes in the lung consistent with our previous investigations of pulmonary oxygen toxicity $(9,10)$. Depending on the concentration of oxygen used and the duration of exposure, these changes have been shown to include increases in the thickness of the blood-air barrier and its components, granular pneumocytes, fibroblasts, collagen, and alveolar macrophages, and decreases in the vol density of the air space, capillary lumen, alveolar and capillary surface areas, and DNA. In the current study, exposure to $80 \%$ oxygen for $18 \mathrm{~d}$ caused significant increased thickness of the blood-air barrier and its components, increase in the vol density of the alveolar wall, in the number of intermediate or transitional epithelial cells, increase in lung collagen and decrease in the blood-air exchange surface area and in lung DNA. The reduced amount of tissue available for morphometric study did not affect the appearance of the changes expected with $80 \%$ oxygen exposure.

The pressure vol measurements in this study were presented both as "full-range" and "simulated tidal vol" compliance (lung recoil) to assess the lungs at an estimated total lung capacity and at an estimated functional residual capacity, respectively. These two methods of presentation were used because other investigators have noted a difference in compliance at total lung capacity compared to lower lung vol (21). Both methods of evaluation showed an increased compliance in the oxygen exposed mice. An increased compliance after hyperoxia has also been observed in neonatal rabbits (22) and adult rats (21). The PV measurement technique in the neonatal rabbit and adult rat experiments were similar to ours in that the lungs were not degassed. Degassing the lung after hyperoxia injury may result in uneven reinflation and may artefactually decrease compliance and therefore give an inaccurate assessment of the mechanical properties of the abnormal lungs (23). Our results are in contrast to a hyperoxia study in the neonatal rat (24) which has reported no change in the air deflation PV curve in rats exposed to $80 \%$ oxygen for $6 \mathrm{~d}$ and decreased compliance in rats exposed to $>95 \%$ oxygen; however, the lungs were degassed before measurement. The increased compliance in the air PV deflation curve of our $80 \%$ oxygen exposed neonatal mice may be due to a stiffening of lung tissue by collagen deposits or to edema, which could increase the tendency for alveolar collapse and lung recoil with lowering of distending pressure $(25,26)$.

The potential beneficial effects of steroids on lung function include reduction in pulmonary edema, decrease in collagen deposition in tissues, decrease in polymorphonuclear recruitment to the lung, increased surfactant synthesis, increase in lung antioxidant activity, and inhibition of prostaglandin and leukotriene synthesis (27). Other pharmacologic effects of steroids include lymphoid tissue and thymus involution, growth suppression, and tissue protein depletion (27). The newborn mice treated with dexamethasone in this study showed changes consistent with known steroid effects. Dexamethasone significantly decreased lung, wet and dry wt and lung water, but did not decrease lung collagen, or the number of polymorphonuclear cells in the lung. It did decrease body growth, thymus wt, brain wt, lung DNA and protein, and the number of lung lymphocytes but did not produce other morphometric change. It is possible that the selection of four experiments for complete morphometric examination could have biased the results, but this is felt to be unlikely as the expected changes with oxygen toxicity were seen, decreased lung lymphocytes were identified with use of dexamethasone, and the lack of morphometric change with dexamethasone was consistent with the lack of change in compliance.

Although dexamethasone produced changes in pulmonary oxygen toxicity in these infant mice, the effects seen were no different in type or degree in the oxygen- or air-exposed animals. The decrease in lung wet wt and lung water in the dexamethasone-treated, oxygen-exposed mice was not accompanied by significant decrease in lung collagen, or thickness of the air-blood barrier, or change in its epithelial or basement membrane components, or improvement in the blood-air exchange surface area-changes that, in a clinical setting, might account for improvements in ventilation.

The lack of morphometric change in the oxygen-exposed mice treated four $\mathrm{d}$ with dexamethasone is consistent with the lack of change in lung compliance. Premature infants with BPD who received dexamethasone in an equivalent dose $(0.5 \mathrm{mg} / \mathrm{kg})$ for 3 $\mathrm{d}$ (with and without several $\mathrm{d}$ of dose reduction) did have an improvement in compliance $(1,3,6)$, which was conventionally 
DEXAMETHASONE EFFECTS ON $\mathrm{O}_{2}$ TOXICITY

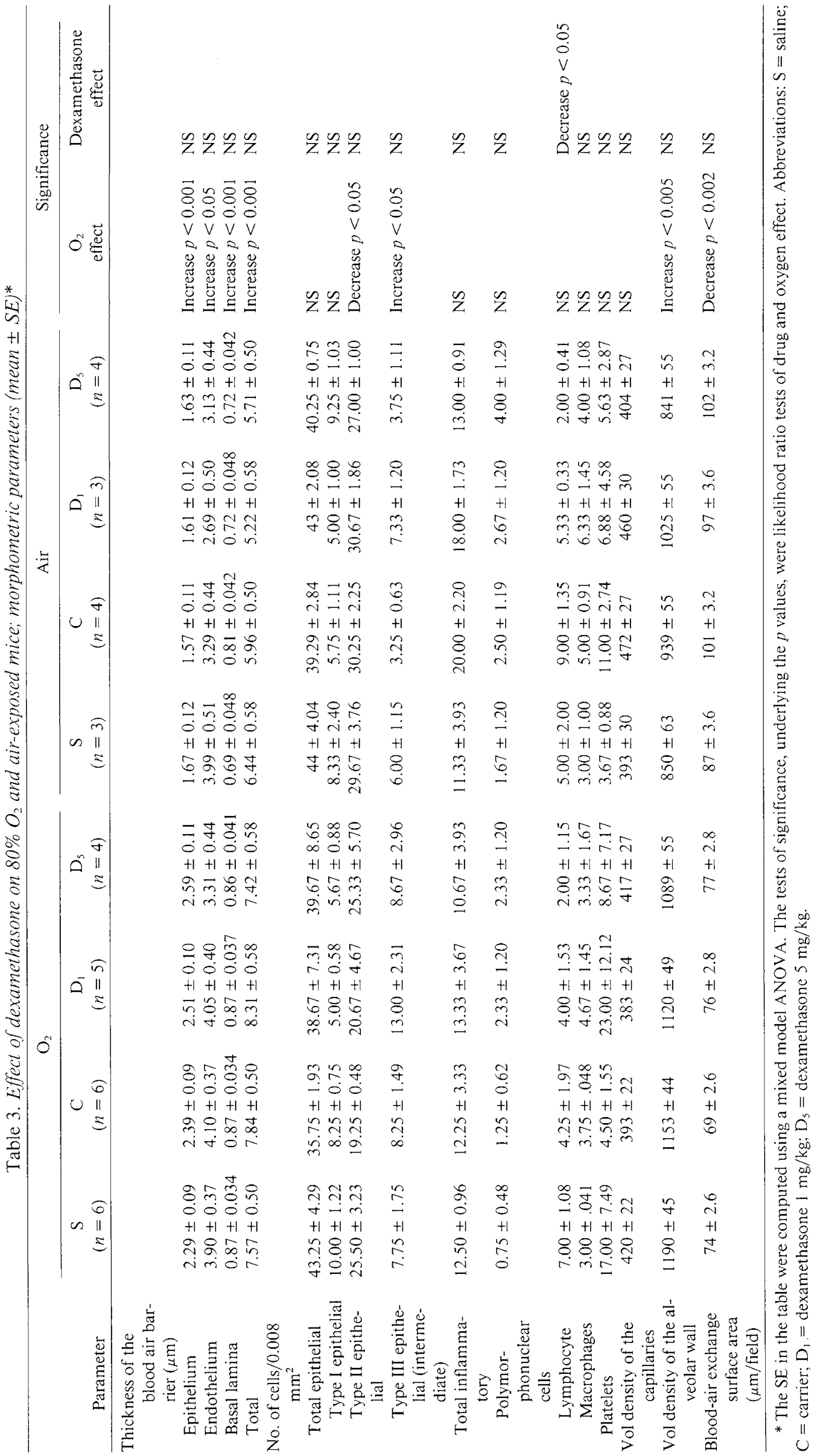




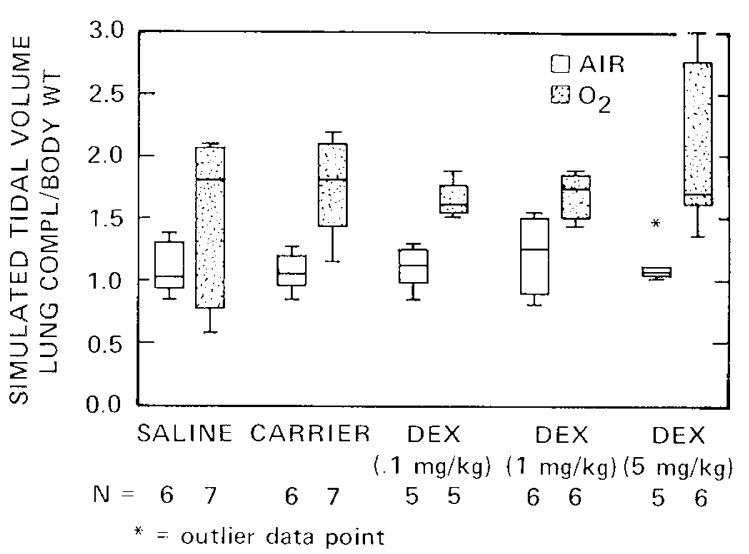

Fig. 1. "Simulated tidal vol" compliance in 18-d-old mice exposed continuously to air or $80 \%$ oxygen and treated from d 14-18 with either saline, carrier, or dexamethasone. The data are presented as box plots (see text under "Results"). An $80 \%$ oxygen exposure significantly increased simulated tidal vol compliance $(p<0.02)$. Dexamethasone had no effect. The figure shows the data ignoring the pairing of animals in the two atmospheres.

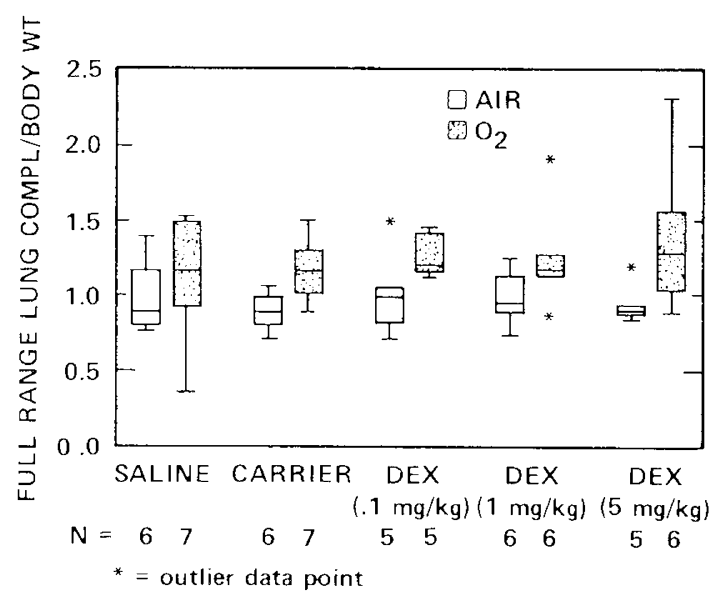

Fig. 2. "Full-range" compliance in 18-d-old mice exposed continuously to air or $80 \%$ oxygen and treated from d 14-18 with either saline, carrier, or dexamethasone. The data are presented as box plots (see text under "Results"). An $80 \%$ oxygen exposure significantly increased "fullrange" compliance $(p<0.02)$. Dexamethasone had no effect. The figure shows the data ignoring the pairing of animals in the two atmospheres.

measured on inflation. Koizumi et al. (28) have also demonstrated a decrease in lung edema and pleural effusion in adult rats who received a single dose of dexamethasone after $48 \mathrm{~h}$ of $>95 \%$ oxygen. They did not measure compliance. Sahebjami et al. (21) exposed adult rats to $98 \%$ oxygen for $96 \mathrm{~h}$ and found that the air deflation PV compliance (lungs degassed) was increased at distending pressures $>20 \mathrm{~cm} \mathrm{H}_{2} \mathrm{O}$ and decreased at lower distending pressures. It is important to point out that these differences were not appreciated unless the lung deflation vol were expressed as a percentage of maximal lung vol. When the lung air deflation volumes were expressed as an absolute volume, the compliance appeared to be decreased in the hyperoxiaexposed rats compared to air-exposed control animals. They also gave a single intramuscular injection of $0.5 \mathrm{mg}$ of $9 \alpha$-fluoromethyl-prednisolone and showed no significant difference in compliance between lungs of corticosteroid-treated and salinetreated rats. Our results in neonatal mice that had a longer exposure to hyperoxia (18 d) and $4 \mathrm{~d}$ of dexamethasone treatment during the last $4 \mathrm{~d}$ of exposure demonstrated an increased air deflation PV compliance (increased lung recoil) after hyperoxia and no change in compliance after corticosteroid treatment.
Riley et al. (29) have studied adult male rats exposed to 90$95 \%$ oxygen for $60 \mathrm{~h}$ and have demonstrated that the saline PV deflation curve showed increased compliance. The air PV method for evaluating lung mechanics shows changes due to tissue components of the lung in addition to effects on the surfactant system; however, the saline inflation method reflects the tissue effects alone. The average alveolar size was increased in our oxygen-exposed mice and in their adult male rats; however, we did not demonstrate any significant difference in lung vol at $20 \mathrm{~cm} \mathrm{H}_{2} \mathrm{O}$ distending pressure or in the lung vol measured by the fluid displacement method. Therefore, we did not conclude that there was evidence for air trapping. The enlargement of alveoli seen in the neonatal hyperoxia-exposed mice may be due to a reduction in alveolar septation. Massaro et al. (30) have shown an increase in alveolar size and decreased alveolar septation in neonatal rats treated with dexamethasone from 4-13 d of life. They were unable to show any change in the saline inflation PV measurements compared to the control animals. In our study, alveolar enlargement was seen in the hyperoxiaexposed mice and alveolar size was unaffected by dexamethasone treatment. We and Riley et al. demonstrated an increase in lung collagen with oxygen exposure that may in part explain the increased deflation compliance (increased lung recoil). As we did not include the saline PV measurements or measurements of pulmonary system surfactant in our study, we could not differentiate these factors. Other studies $(21,31-35)$ suggest that a change in compliance after hyperoxia exposure may be attributed to a derangment of the surfactant system as saline PV measurements show the same tissue compliance.

Although the decrease in lung wet wt and lung water induced by dexamethasone may be beneficial in chronic pulmonary oxygen toxicity, the potential improvement in lung mechanics is less clear, and the treatment is not without serious side effects. Even the short 4-d exposure to the drug resulted in a significant decrease in thymic wt, number of lymphocytes in the lung, and body wt gain. Brain wt and lung DNA also were reduced by dexamethasone treatment. The decrease in thymus wt seen in this study even with the lowest $(0.1 \mathrm{mg} / \mathrm{kg})$ dose of dexamethasone was impressive. Unfortunately, such a thymolytic effect and growth inhibition seen with the use of dexamethasone could also occur in the clinical setting of the seriously ill, poorly growing, immune-deficient, premature infant. Use of dexamethasone could augment these problems.

In this study in 2-wk-old mice, a difference in the effect of the 1 - and $5-\mathrm{mg} / \mathrm{kg}$ doses of dexamethasone could not be distinguished. The effective dose of the drug in this setting would appear to be $1 \mathrm{mg} / \mathrm{kg} / \mathrm{d}$. This is in the dose range used in the three fully reported studies of the effect of dexamethasone in chronic BPD in human infants $(1-3)$. In our study, mortality with dexamethasone occurred in one animal in both oxygen and air group with the $5-\mathrm{mg} / \mathrm{kg}$ dose. The single dead animal available for examination did not have intraventricular hemorrhage or microscopic evidence of infection, and blood culture was sterile.

Dexamethasone did decrease lung wet wt and lung water in infant mice with chronic pulmonary oxygen toxicity but did not change pulmonary compliance. The drug also cause significant reduction in body, brain, thymus, and lung growth. If these parameters change in a similar fashion in human infants with $\mathrm{BPD}$, dexamethasone should be used with great caution even for short-term clinical management.

\section{REFERENCES}

1. Mammel MC, Green PG, Johnson DE, Thompson TR 1983 Controlled trial of dexamethasone therapy in infants with bronchopulmonary dysplasia. Lancet 1:1356-1358

2. Mammel MC, Fiterman C, Coleman M, Boros SJ 1987 Short-term dexamethasone therapy for bronchopulmonary dysplasia: acute effects and 1 year followup. Dev Pharmacol Ther 10:1-11

3. Avery GB, Fletcher AB, Kaplan M, Brudno DS 1985 Controlled trial of 
dexamethasone in respirator dependent infants with bronchopulmonary dysplasia. Pediatrics 75:106-111

4. Pomerance J, Puri AR 1980 Treatment of severe neonatal bronchopulmonary dysplasia with dexamethasone. Pediatr Res 14(suppl):649(abstr)

5. Pomerance J, Puri AR 1982 Treatment of severe neonatal bronchopulmonary dysplasia with dexamethasone. Pediatr Res I6(suppl):395(abstr)

6. Ariagno RL, Sweeney TJ, Baldwin D, Inguillo D, Martin D 1987 Dexamethasone effects on lung function and risks in three week old ventilator dependent preterm infants. Am Rev Resp Dis 135:125(abstr)

7. Ariagno RL, Wilson DM, Inguillo D, Martin D 1987 The effect of dexamethasone on adrenal responsiveness in ventilator dependent preterm infants with bronchopulmonary dysplasia (BPD). Am Rev Resp Dis 135:125(abstr)

8. Northway WH Jr, Petriceks RV, Shahinian L 1972 Quantitative aspects of oxygen toxicity in the newborn: inhibition of lung DNA synthesis in the mouse. Pediatrics 50:67-72

9. Bonikos DS, Bensch KG, Northway WH Jr 1976 Oxygen toxicity in the newborn: the effect of chronic continuous $100 \%$ oxygen exposure on the lungs of newborn mice. Am J Pathol 85:623-650

10. Pappas CTE, Obara H, Bensch KG, Northway WH Jr 1983 Effect of prolonged exposure to $80 \% \mathrm{O}_{2}$ on the lung of the newborn mouse. Lab Invest 48:735 748

11. Huszar G, Maiocco J, Naftolin F 1980 Monitoring of collagen and collagen fragments in chromatography of protein mixtures. Anal Biochem 105:42.4 429

12. Lowry OH, Rosebrough NJ, Farr AL, Randall RJ 1951 Protein measurement with the Folin phenol reagent. J Biol Chem 193:265-275

13. Kennel D 1967 Use of filters to separate radioactivity in RNA, DNA and protein. In: Grossman L, Molduve K (eds) Methods in Enzymology, vol 12. Academic Press, New York, pp 686-693

14. Burton K 1956 A study of the conditions and mechanisms of the diphenylamine reaction for the colorimetric estimation of desoxyribonucleic acid. Biochem J 62:315-323

15. Perrone-Capano C. D'Onotrio G, Giuditta A 1982 DNA turnover in rat cerebral cortex. J Neurochem 38:52-56

16. Scherle W 1970 A simple method for volumetry of organs in quantitative sterology. Mikroskopie 26:57-60

17. Weibel E 1963 Morphometry of the Human Lung. Academic Press, New York

18. Weibel E 1980 Stereological Methods, vol 1. Academic Press, New York

19. Cochran WG, Cox GM 1957 Experimental Designs. John Wiley and Sons,
New York, pp 293-316

20. Cochran WG, Cox GM 1957 Experimental Designs. John Wiley and Sons, New York, pp 148-182

21. Sahebjami H, Gacad G, Massaro D 1974 Influence of corticosteroids on recovery from oxygen toxicity. Am Rev Respir Dir 1 10:566-571

22. Ward JA, Roberts RJ 1984 Vitamin E inhibition of the effects of hyperoxia on the pulmonary surfactant system of the newborn rabbit. Pediatr Res 18:329334

23. Gross NJ 1981 Mechanical properties of mouse lungs: effects of degassing on normal, hyperoxic, and irradiated lungs. J Appl Physiol 51:391-398

24. Bucher JR, Roberts R 1981 The development of the newborn rat lung in hyperoxia: a dose response study of lung growth, maturation, and changes in antioxidant enzyme activities. Pediatr Res 15:999-1008

25. Hoppin FG Jr and Hilderbrandt J 1977 Mechanical properties of the lung. In: West JB Bioengineering aspects of the lung, Marcel Dekker, New York, pp. $83-162$

26. Said SI, Avery ME, Davies RK, Banerjee CM, El-Gohary M 1965 Pulmonary surface activity in induced pulmonary edema. $J$ Clin Invest 44:458-464

27. Ariagno RL 1988 Use of steroids. In: Merritt TA, Northway WH Jr, Boynton BR (eds) Bronchopulmonary dysplasia. Blackwell Scientific Publications, Boston, pp 375-402

28. Koizumi M, Frank L, Massaro D 1985 Oxygen toxicity in rats. Am Rev Respir Dis 131:907-911

29. Riley DJ, Berg RA, Edelman NH, Prockop DJ 1980 Prevention of collagen deposition following pulmonary oxygen toxicity in the rat by cis-4-hydroxyL-Proline. J Clin Invest 65:643-651

30. Massaro D, Teich N, Maxwell S, Massaro G, Whitney P 1985 Postnatal development of alveoli. J Clin Invest 76:1297-1305

31. Gross NJ, Smith DM 1984 Methylprednisolone increases the toxicity of oxygen in adult mice. Am Rev Respir Dis 129:805-810

32. Beckman DL, Weiss HS 1969 Hyperoxia compared to surfactant washout on pulmonary compliance in rats. J Appl Physiol 26:700-709

33. Gross NJ, Smith DM 1981 Impaired surfactant phospholipid metabolism in hyperoxic mouse lungs. J Appl Physiol 51:1198-1203

34. Brumley GW, Tuggle B, Luxner L, Crapo JD 1979 Disaturated phosphatidyl choline in rat lungs with altered numbers of type 2 alveolar epitheal cells. Am Rev Resp Dis 119:461-470

35. Gilder H, McSherry CK 1976 Phosphatidyl choline synthesis and pulmonary oxygen toxicity. Biochem Biophys Acta 441:48-56 